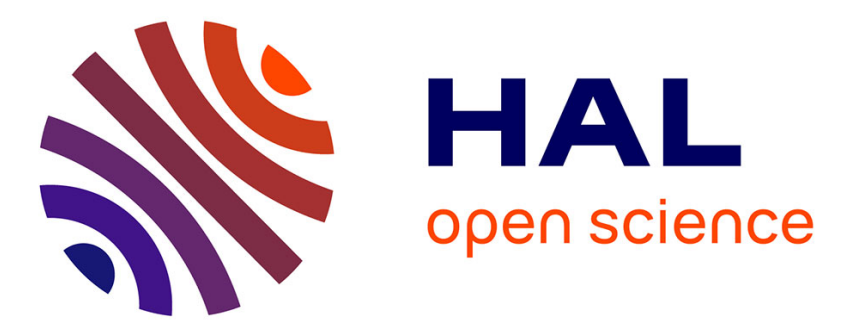

\title{
Use of supercritical CO2-aided and conventional melt extrusion for enhancing the dissolution rate of an active pharmaceutical ingredient
}

Zsombor Kristof Nagy, Martial Sauceau, Katalin Nyul, Élisabeth Rodier, Balzs Vajna, Gyoergy Marosi, Jacques Fages

\section{To cite this version:}

Zsombor Kristof Nagy, Martial Sauceau, Katalin Nyul, Élisabeth Rodier, Balzs Vajna, et al.. Use of supercritical CO2-aided and conventional melt extrusion for enhancing the dissolution rate of an active pharmaceutical ingredient. Polymers for Advanced Technologies, 2012, 23 (5), p. 909-918. 10.1002/pat.1991 . hal-01618290

\section{HAL Id: hal-01618290 \\ https://hal.science/hal-01618290}

Submitted on 24 Nov 2017

HAL is a multi-disciplinary open access archive for the deposit and dissemination of scientific research documents, whether they are published or not. The documents may come from teaching and research institutions in France or abroad, or from public or private research centers.
L'archive ouverte pluridisciplinaire HAL, est destinée au dépôt et à la diffusion de documents scientifiques de niveau recherche, publiés ou non, émanant des établissements d'enseignement et de recherche français ou étrangers, des laboratoires publics ou privés. 


\title{
Use of supercritical $\mathrm{CO}_{2}$-aided and conventional melt extrusion for enhancing the dissolution rate of an active pharmaceutical ingredient
}

\author{
Zsombor Kristóf Nagy ${ }^{a *}$, Martial Sauceau ${ }^{b}$, Katalin Nyúl ${ }^{a}$, Elisabeth Rodier ${ }^{b}$, \\ Balázs Vajna ${ }^{a}$, György Marosi ${ }^{a}$ and Jacques Fages ${ }^{b}$
}

\begin{abstract}
Dispersing at the molecular level a drug in a polymer matrix is a major challenge to be addressed by the pharmaceutical industry to enhance its bioavailability or to control its release. Melt extrusion and supercritical $\mathrm{CO}_{2}$-aided melt extrusion of solid pharmaceutical formulations were performed to enhance the dissolution rate of carvedilol, taken as a model of poorly soluble drug. The presence of the drug improved the processability of the polyacrylate matrix (Eudragit E) through its plasticizing effect. The supercritical method was found gentle compared with melt extrusion owing to the shorter residence time and lower processing temperature and melt viscosity. No traces of decomposition of the drug could be detected after the supercritical extrusion process based on capillary electrophoresis results. This extrusion process resulted in effective homogenization of the components and amorphization of the drug according to Raman mapping, Fourier transform infrared spectrometry, X-ray diffraction, and polarized light microscopy. The kinetics of dissolution can be dramatically improved.
\end{abstract}

Keywords: extrusion; supercritical $\mathrm{CO}_{2}$ extrusion; solid dispersion; solid solution; amorphization; enhanced drug dissolution rate

\section{INTRODUCTION}

The term "hot-melt extrusion" (HME) is used in pharmaceutical technology for describing the process that converts a raw material into a product of uniform shape and density by forcing it through a die under controlled temperature, pressure, and shear rate. ${ }^{[1]}$ Pharmaceutical extrusion represents an efficient manufacturing technology to disperse drugs in a melt up to a true molecular solution of a pharmaceutical ingredient into a polymeric matrix. ${ }^{[2]}$ Most of the applications describe the preparation of solid dispersions by HME either to increase the aqueous solubility and oral bioavailability of the active substance or to control its release. The mostly reported advantages of HME are as follows: (i) avoidance of organic solvent; (ii) reduction of processing steps (one-pot method); (iii) elimination of the good compressibility requirement for the active ingredients and the excipients; (iv) high level of drug content; (v) even dispersion of the drug throughout the matrix; and (vi) improved bioavailability through drug solubilization or molecular-level dispersion in water-soluble matrix. ${ }^{[3]}$

One of the major drawbacks of HME is that it can be applied only for producing thermally stable pharmaceuticals. For a number of drugs, proteins, and excipients, HME cannot be used unless a plasticizer is added in order to reduce the viscosity of the mixture and to lower the processing temperature applicable in the extruder. However, these additives remain in the product, altering its properties and performance.

In this context, supercritical carbon dioxide $\left(\mathrm{scCO}_{2}\right)$ represents an interesting alternative. The injection of $\mathrm{scCO}_{2}$ in the extrusion process modifies the rheological properties of the polymer, and also, $\mathrm{scCO}_{2}$ acts as a blowing agent at the die exit. ${ }^{[4]}$ In the barrel of the extruder, the reduction of viscosity decreases the mechanical constraints and the operating temperature. At the die exit, the pressure drop induces a thermodynamic instability in the polymer matrix, generating a large number of bubbles, which can grow until the foam is rigidified when temperature drops below the glass transition temperature, $T_{\mathrm{g}}$. Thus, combining extrusion with $\mathrm{scCO}_{2}$ allows using relatively fragile or thermally sensitive molecules, like pharmaceutical molecules, without any residue in the final material.

For the extrusion of pharmaceuticals, copolymers derived from acrylic acid and methacrylates, such as Eudragit types, are wellknown matrices. Because of their multifunctional nature, unique properties, and good biocompatibility, these polymers are considered to be of common grades for the coating of pharmaceuticals. ${ }^{[5]}$ In particular, Eudragit E, because of its tertiary

\footnotetext{
* Correspondence to: Z. K. Nagy, Budapest University of Technology and Economics, Organic Chemistry and Technology Department, 1111 Budapest, Budafoki Str. 8, Hungary.

E mail: nagyzsomborkristof@gmail.com

a Z. K. Nagy, K. Nyúl, B. Vajna, G. Marosi

Budapest University of Technology and Economics, Organic Chemistry and Technology Department, $\mathrm{H}-1111$ Budapest, Hungary

b M. Sauceau, E. Rodier, J. Fages

Université de Toulouse, École des Mines Albi, CNRS, Centre RAPSODEE, F-81013 Albi, France
} 
amine groups, forms a coating soluble in gastric fluid in acidic $\mathrm{pH}^{[6]}$ Eudragit $\mathrm{E}$ has already been successfully implemented for HME. Six et al. ${ }^{[7]}$ described the HME of the poorly water-soluble itraconazole with Eudragit E100 polymeric carrier. Melt extrusion of this drug with Eudragit $E$ polymer resulted in significantly enhanced dissolution rate. More recently, Verreck et al. showed that pressurized carbon dioxide, acting as a removable plasticizer and foaming agent, reduces the melt extrusion temperature of several pharmaceutically acceptable polymers, including Eudragit E100. ${ }^{[8]}$ Lately, Nikitine et al. studied the correlation between operating conditions and foam structures of Eudragit E100. ${ }^{[9]}$ This work was also completed by the study of the influence of $\mathrm{scCO}_{2}$ on the polymer flow of Eudragit E100 in the extruder. ${ }^{[10-12]}$

Lipid soluble chemicals, such as carvedilol (CAR), are almost insoluble in water. Therefore, they are poorly absorbed through the gastrointestinal tract. CAR is a nonselective $\beta$-adrenergic blocking agent with an a-blocking activity. ${ }^{[13]}$ According to the Biopharmaceutics Classification System, it belongs to the class II drug having low solubility and good permeability. However, if CAR is well absorbed after oral administration, it is subject to firstpass metabolism in the liver resulting in only about $25 \%$ absolute bioavailability. ${ }^{[14]}$ Eudragit E100 has already been used to improve the bioavailability of CAR. Recently, E100 nanoparticles containing CAR were prepared by nanoprecipitation. ${ }^{[15]}$ Finally, high encapsulation efficiency was obtained, and the release of CAR from the nanoparticles was achieved within $5 \mathrm{~min}$.

In this work, melt extrusion and $\mathrm{scCO}_{2}$-coupled extrusion was used to generate solid dosage form based on Eudragit E100 with CAR drug according to the method elaborated for producing foams of this polymer. ${ }^{[9]}$ The aim was to obtain similar drug release rate of CAR as it was achieved by nanoprecipitation and to investigate the potential advantages of applying $\mathrm{sCCO}_{2}$ during the extrusion process. For achieving rapid dissolution, the feasibility of an amorphous solid dispersion or solution of CAR and Eudragit E100 was investigated in order to avoid the necessity of overcoming the crystal lattice energy of CAR. In the case of solid solution, the rate-determining step of CAR release is the dissolution of Eudragit $E$, which is quite rapid in acidic media such as the gastric fluid. The properties of the extrudates were investigated by several methods to study the morphology, the crystallinity, the degradation, the mixing, and the dissolution profile.

\section{MATERIALS AND METHODS}

\section{Materials}

Carvedilol (Fig. 1) from Sigma-Aldrich (Budapest, Hungary) with purity $\geq 98 \%$ was used in this work. The melting point of CAR is $117^{\circ} \mathrm{C}{ }^{[16]} \mathrm{CO}_{2}$ was purchased from Air Liquide (Paris, France) and Eudragit E (E100, Fig. 2) from IMCD (Saint-Denis La Plaine, France). Eudragit is an amorphous polymer with an average molecular

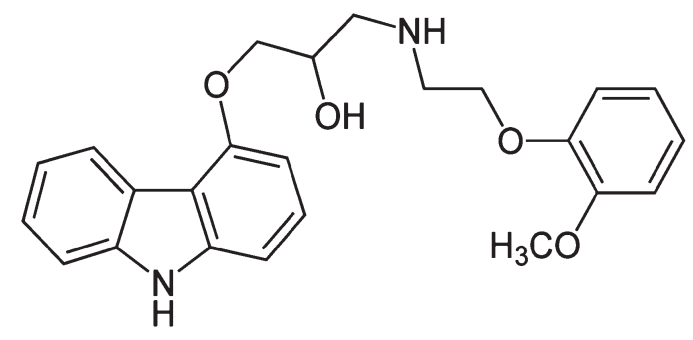

Figure 1. Carvedilol formula.

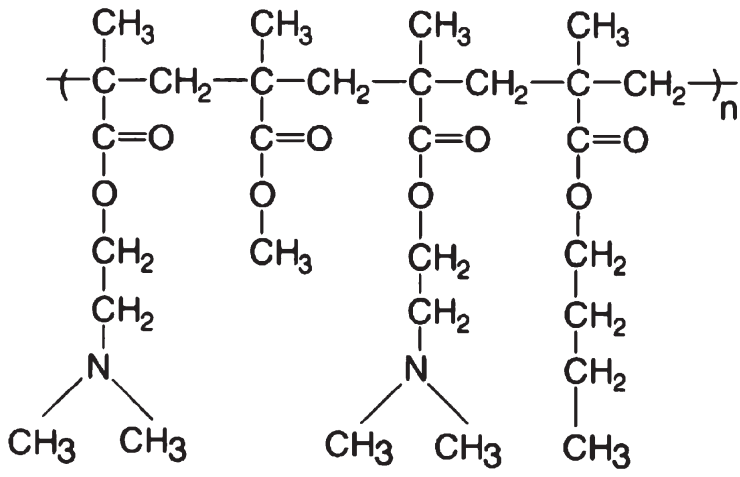

Figure 2. Eudragit E formula.

weight of about $150000 \mathrm{~g} \mathrm{~mol}^{-1}$. Its glass transition temperature, measured by differential scanning calorimetry (ATG DSC 111, SETARAM, Caluire, France), is in the range $4552^{\circ} \mathrm{C}$. A rheological study at atmospheric pressure was performed ${ }^{[17]}$, and the polymer exhibited a pseudoplastic behavior with a viscosity similar to those of molten polymers (around $10^{3} \mathrm{Pas}$ ). These previous characterizations helped in choosing the operating conditions to process Eudragit E100 by extrusion.

\section{Extrusion coupled with supercritical $\mathrm{CO}_{2}$}

Figure 3 shows the experimental set up, which has previously been detailed elsewhere. ${ }^{[9,10]}$ The single-screw extruder has a $30-\mathrm{mm}$ screw diameter and a length to diameter $(L / D)$ ratio of 35 (Rheoscam, SCAMEX, Crosne, France). A large L/D ratio generally allows increasing not only the capacity of mixing and melting but also energy consumption. The first conical part of the screw has an $L / D$ ratio of 20 and allows the transport of solid polymers and then their melting and plasticizing. Then, the screw has a cylindrical geometry from the first gastight ring to the die with an $L / D$ ratio of 15 . Two restriction rings have been fitted out in order to prevent $\mathrm{scCO}_{2}$ from backflowing. The diameter of the die is $1 \mathrm{~mm}$ and its length is $11.5 \mathrm{~mm}$.

The temperature inside the barrel is measured at five locations: $T_{\mathrm{a}}$ and $T_{\mathrm{b}}$ before the $\mathrm{CO}_{2}$ injection, $T_{\mathrm{c}}$ and $T_{\mathrm{d}}$ after the injection, and $T_{\mathrm{e}}$ in the die. In this study, the temperatures of the different zones were fixed as follows: $T_{\mathrm{a}}=125^{\circ} \mathrm{C}, T_{\mathrm{b}}=T_{\mathrm{c}}=$ $T_{\mathrm{d}}=135^{\circ} \mathrm{C}$ and $T_{\mathrm{e}}=130^{\circ} \mathrm{C}$ and the measured temperatures were stabilized at the predetermined values $\left( \pm 2^{\circ} \mathrm{C}\right)$ during the experiments. They were kept in all cases higher than the melting point of CAR $\left(117^{\circ} \mathrm{C}^{[16]}\right)$, allowing it to be melted and thus increasing the possibility for obtaining solid solution.

The temperature and the pressure of the polymer inside the extruder were measured by means of three pressure gauges $\left(P_{1}\right.$, $P_{2}$, and $\left.P_{3}\right)$ and two temperature sensors $\left(T_{1}\right.$ and $\left.T_{2}\right)$. Errors associated to pressure and temperature sensors were about $0.2 \mathrm{MPa}$ and $3.3^{\circ} \mathrm{C}$, respectively.

$\mathrm{CO}_{2}$ was pumped from a cylinder by a syringe pump (260D, ISCO, Lincoln, NE, USA) regulated at $7^{\circ} \mathrm{C}$. It was then introduced at a constant volumetric flow rate and at a pressure slightly higher than $P_{1}$. The $\mathrm{CO}_{2}$ injector was positioned at an $L / D$ ratio of 20 from the feed hopper. The pressure and the volumetric $\mathrm{CO}_{2}$ flow rate were measured within the syringe pump.

At the beginning of the extrusion process, pure E100 was fed in the extruder. Before the injection of $\mathrm{scCO}_{2}$, the torque was controlled by the rotating speed of the screw (higher rotating 


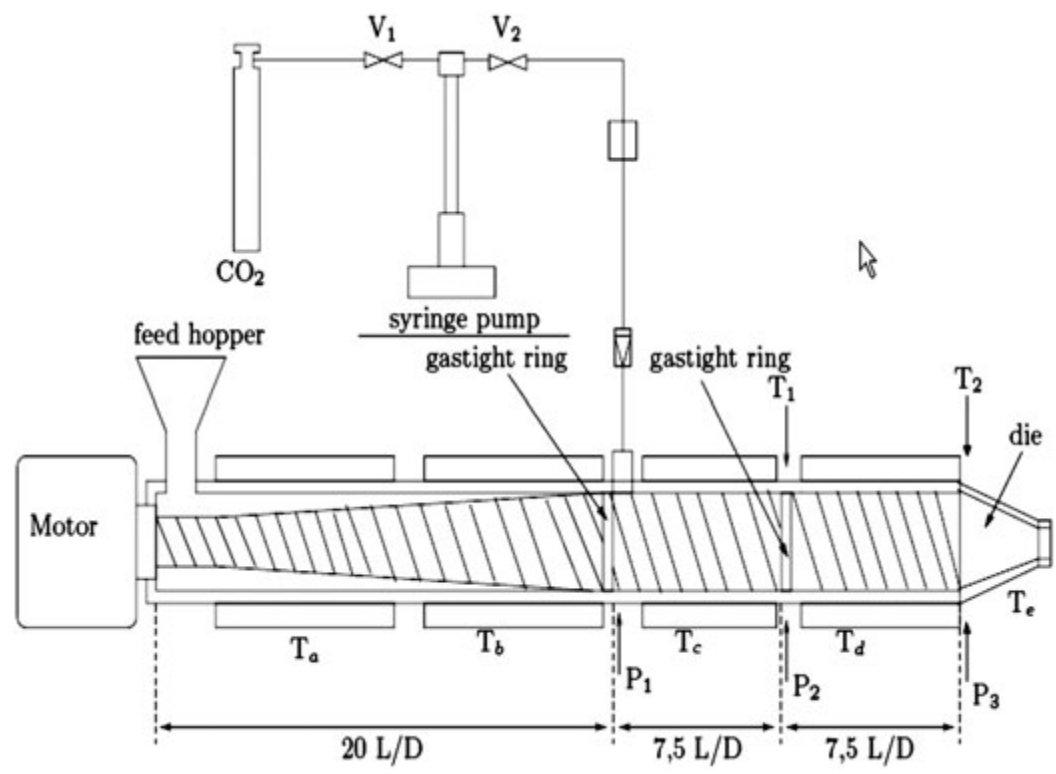

Figure 3. Experimental device.

speed resulted in higher torque) and was kept at high values close to the established alarm limit $(120 \mathrm{Nm})$ to ensure high production rate and short residence time. Once steady-state conditions had been reached with E100, drug polymer mixture was introduced through the hopper. $\mathrm{scCO}_{2}$ was introduced into the barrel once the drug polymer mixture had reached the die. During the $\mathrm{scCO}_{2}$ injection, the torque decreased, and the rotation speed could therefore be increased to reach higher production rates and shorter residence time. When steady-state conditions had been reached again, extrudates were collected and air cooled at ambient temperature. The samples were obtained under the operating conditions given in Table 1. The sampling time and the mass of the collected samples were measured in order to determine the mass flow rate. Extrudates were then ground by an IKA MF10 microfine (MF) grinder equipped with a MF 10.2 impact grinding head (Staufen, Germany). The applied rotation speed was $3000 \mathrm{rpm}$ and sieve was MF $2.0 \mathrm{~mm}$, thus the obtained particle size was less than $2 \mathrm{~mm}$. The grinding was carried out using the same method in all cases. Based on optical and scanning electron microscopy analyses, the sizes of majority of the particles were between 100 and $1500 \mu \mathrm{m}$.

Compositions and operating conditions for the different samples are presented in Table 1. The $\mathrm{CO}_{2}$ flow rate was fixed at $0.25 \mathrm{~cm}^{3} \mathrm{~min}^{-1}$, and two drug mass contents were tested: $5 \%$ and $20 \%$.

\section{Scanning electron microscopy}

Morphology of the samples was investigated by a JEOL 6380LVatype scanning electron microscope (Tokyo, Japan). Each specimen was fixed by conductive double-sided carbon adhesive tape and gold-coated using a JEOL 1200 apparatus (Tokyo, Japan) in order to avoid electrostatic charging.

\section{Fourier transform infrared spectrometry}

$\mathrm{KBr}$ tablet sample preparation method was used for the Fourier transform infrared (FTIR) spectrometry measurement of untreated materials and ground extrudates. The obtained tablets were

Table 1. Compositions and operating conditions of the samples

\begin{tabular}{|c|c|c|c|c|c|}
\hline Exp & CAR (mass\%) & $\mathrm{CO}_{2}\left(\mathrm{~cm}^{3} \mathrm{~min}^{-1}\right)$ & $\begin{array}{l}\text { Pressure }\left(P_{1}\right) \text { in the barrel } \\
\text { at } \mathrm{CO}_{2} \text { injection (bar) }\end{array}$ & $\begin{array}{l}\text { Screw rotation } \\
\text { speed (rpm) }\end{array}$ & Flow rate $(\mathrm{g} \mathrm{min}-1)$ \\
\hline 1CARO & 0 & 0 & 165 & 5 & 5.5 \\
\hline 2CAR5 & 5 & 0 & 135 & 5 & 5.5 \\
\hline 3CAR5SC & 5 & 0.25 & 78 & 5 & 5.5 \\
\hline 4CAR5SC & 5 & 0.25 & 85 & 7 & 7.7 \\
\hline 5CAR5SC & 5 & 0.25 & 112 & 10 & 11 \\
\hline 6CAR20 & 20 & 0 & 115 & 5 & 5.5 \\
\hline 7CAR20SC & 20 & 0.25 & 57 & 5 & 5.5 \\
\hline 8CAR20SC & 20 & 0.25 & 74 & 7 & 7.7 \\
\hline 9CAR20SC & 20 & 0.25 & 90 & 10 & 11 \\
\hline
\end{tabular}


analyzed by Bruker Tensor 37-type spectrometer equipped with deuterated triglycine sulfate detector (Ettlingen, Germany) in the range of $4000400 \mathrm{~cm}^{-1}$ with a resolution of $4 \mathrm{~cm}^{-1}$.

\section{Polarized light microscopy}

The crystalline and amorphous phases of the samples were distinguished by Amplival, Carl Zeiss Jena polarized light microscope (Jena, Germany).

\section{X-ray diffraction}

Powder X-ray diffraction patterns were recorded by a PANalytical X'pert Pro MDP X-ray diffractometer (Almelo, The Netherlands) using $\mathrm{Cu}$ Ka radiation (1.542 $\AA$ ) and $\mathrm{Ni}$ filter. The applied voltage was $40 \mathrm{kV}$ whereas the current was $30 \mathrm{~mA}$. The untreated materials, physical mixture (mixed in a mortar by a pestle) and ground extrudates were analyzed for angles $2 \theta$ between $2^{\circ}$ and $42^{\circ}$.

\section{Capillary electrophoresis}

The chemical stability of the extruded samples was characterized by capillary electrophoresis. The experiments were performed using a $\mathrm{HP}^{3 \mathrm{D}} \mathrm{CE}$ fully automated instrument, Agilent Technologies (Santa Clara, CA, USA), equipped with diode-array detector and Chemstation software for data handling. The fused silica capillary (inner diameter $50 \mu \mathrm{m}$, effective length $30 \mathrm{~cm}$ ) was thermostated at $25^{\circ} \mathrm{C}$ and was preconditioned prior all runs by flushing with Milli-Q water $(0.5 \mathrm{~min}), 0.1 \mathrm{M} \mathrm{NaOH}(1 \mathrm{~min})$ Milli-Q water $(0.5 \mathrm{~min})$ and the buffer $\left(2.5 \mathrm{~min}, 60 \mathrm{mM} \mathrm{NaH}_{2} \mathrm{PO}_{4}, \mathrm{pH}=2.5\right.$ adjusted with $\mathrm{H}_{3} \mathrm{PO}_{4}$ ). The samples were dissolved with $0.1 \mathrm{M} \mathrm{HCl}$ and were injected hydrodynamically $(5 \mathrm{kPa}, 4 \mathrm{~s})$. The applied electrostatic potential was $20 \mathrm{kV}$ during the measurement. Three parallel measurements of each sample were carried out.

\section{Raman microspectrometry}

Raman-mapping spectra were collected using a Horiba Jobin Yvon LabRAM system (Longjumeau, France) coupled with a frequency doubled Nd:YAG laser source $(532 \mathrm{~nm})$ and an Olympus BX-40 optical microscope. Objectives of $\times 10$ and $\times 100$ magnifications were used for optical imaging and spectrum acquisition.

The Raman spectra of the pure materials were collected with a $\times 100$ objective without any sample preparation. The surface of the cut cross-section of each sample was mapped by Raman microscope in order to investigate the mixing efficiency. In the case of foamed samples, the tablet was compressed (Camilla OL95, Manfredi, Torino, Italy) to achieve a flat surface for Raman mapping. The reference sample was also a compressed tablet of the physical mixture (mixed in a mortar by a pestle) of CAR and E100 (mass ratio 1:4). The measured area was approximately $1 \mathrm{~mm} \times 1 \mathrm{~mm}$ in all cases. The component concentrations were estimated with classic least squares method. Visualized score maps were created with LabSpec 5.41 (Horiba Jobin Yvon).

\section{Determination of drug content}

Samples equivalent to $10 \mathrm{mg}$ of CAR were placed into a volumetric flask $\left(1 \mathrm{dm}^{3}\right)$ and were diluted with $0.1 \mathrm{M} \mathrm{HCl}$. After complete dissolution and homogenization, the concentration of CAR was determined by UV spectrophotometry at $242 \mathrm{~nm}$ (Hewlett-Packard HP 8452A, Palo Alto, CA, USA). Ten parallel tests were analyzed statistically.

\section{In vitro dissolution measurement}

The dissolution studies were performed using an Erweka DT6 dissolution tester (USP II apparatus, Heusenstamm, Germany). Samples equivalent to $12.5 \mathrm{mg}$ of CAR were added as a powder directly in the dissolution vessel containing $900 \mathrm{ml} 0.1 \mathrm{M} \mathrm{HCl}$ maintained at $37 \pm 0.5^{\circ} \mathrm{C}$ and stirred at $50 \mathrm{rpm}$. Samples ( $5 \mathrm{ml}$ ) were collected periodically and the concentration of CAR was determined by UV spectrophotometry at $242 \mathrm{~nm}$ (Hewlett-Packard HP $8452 \mathrm{~A}$ ) using a diode-array detector at $242 \mathrm{~nm}$. Six parallel tests were performed and analyzed statistically.

\section{RESULTS AND DISCUSSION}

\section{Comparison of the melt and supercritical $\mathrm{CO}_{2}$-aided extrusion techniques}

To improve the dissolution rate of CAR by forming solid dispersion or solution of the drug in the E100 matrix, both melt extrusion and $\mathrm{sCCO}_{2}$-aided melt extrusion processes were performed (Table 1). The viscosity of the material in the barrel was correlated with the torque. Without the injection of $\mathrm{scCO}_{2}$, the maximum applicable rotation speed was $5 \mathrm{rpm}$. In contrast, while injecting $\mathrm{SCCO}_{2}$, the torque significantly decreased, and the rotation speed could be increased stepwise up to $10 \mathrm{rpm}$. The torque at $10 \mathrm{rpm}$ was lower than the value corresponding to $5 \mathrm{rpm}$ without $\mathrm{scCO}_{2}$ (Fig. 4). This is demonstrated by experiments 2 and 5 at $5 \%$ of CAR and 6 and 9 at $20 \%$ of CAR. A gain in the maximal throughput, from 5.5 to $11 \mathrm{~g} / \mathrm{min}$ (cf. Table 1), was also observed as well as a shortened residence time. These effects are consistent with a lower viscosity, which can be attributed to the plasticization effect of carbon dioxide. The application of $\mathrm{scCO}_{2}$ in the field of pharmaceutical extrusion has two noteworthy advantages as for the CAR stability point of

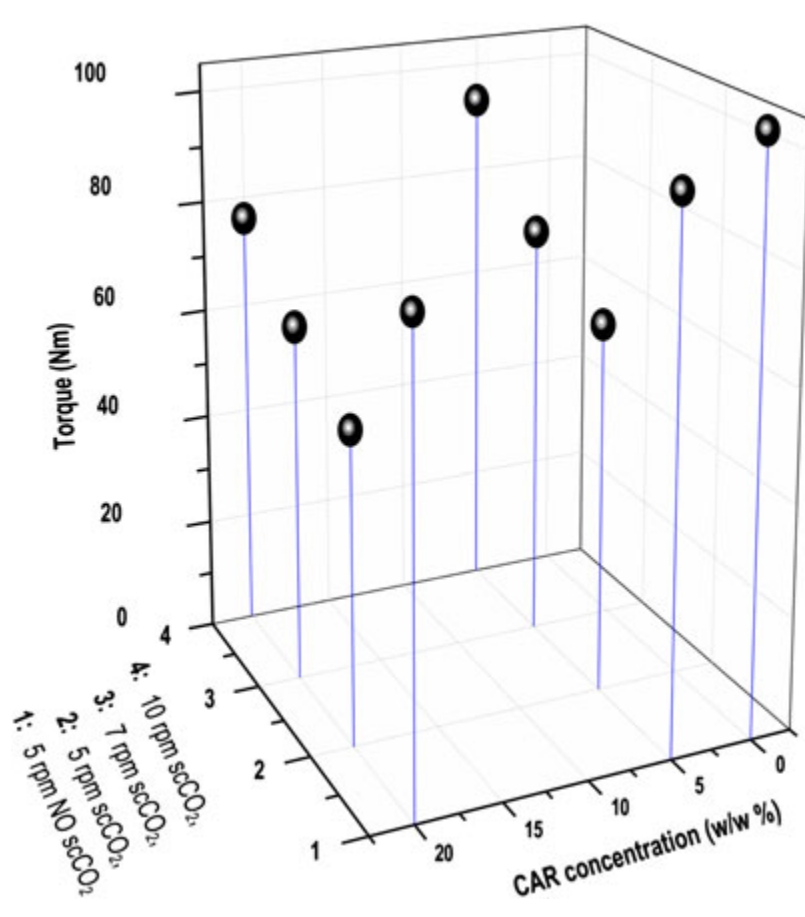

Figure 4. The measured torque during the extrusion in the function of carvedilol (CAR) concentration, screw rotation speed, and $\mathrm{CO}_{2}$ addition. 
view. Because of the dissolution of $\mathrm{CO}_{2}$ in the material processed, operating temperature can be decreased ${ }^{[8]}$, and the mass flow rate can be increased because of the decrease of the viscosity. If higher mass flow is achieved, the residence time of the material can be significantly shortened; furthermore, the productivity is increased. Higher throughput and lower temperature result in a lower risk of decomposition and a lower amount of impurities (decomposition products), which can be kept under the permitted limit.

In addition to the effect of $\mathrm{scCO}_{2}$, the introduction of the active ingredient provided a plasticizing effect too, as evidenced by the decreasing torque, from $104 \mathrm{~N} \mathrm{~m}$ to $96 \mathrm{~N} \mathrm{~m}$ with $5 \%$ drug and $83 \mathrm{~N} \mathrm{~m}$ with $20 \%$ drug (cf. experiments without $\mathrm{scCO}_{2}$ in Fig. 4). CAR, being a rather small molecule, proved to play the role of a plasticizer. E100 CAR mixtures exhibit lower torque than pure E100, which suggests a decrease of the viscosity.

The photographs of E100 CAR extrudates are shown in Fig. 5. The extrudates made by classic extrusion process (A) were glassy and transparent. In contrast, the extrudates made by $\mathrm{scCO}_{2}^{-}$ aided extrusion (B) were opaque because of the reflections caused by the internal surfaces of small bubbles formed during the extrusion.

\section{Scanning electron microscopy}

The scanning electron microscopy images of extrudates are shown in Fig. 6 . The specific surface area is clearly larger in the case of the foamed samples (with $\mathrm{CO}_{2}$ ) providing extended

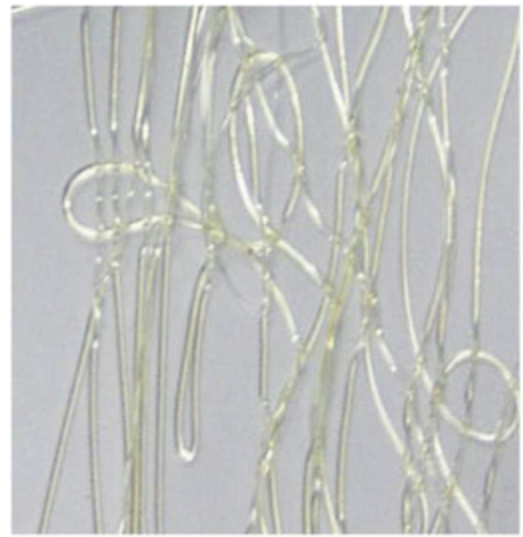

(A)

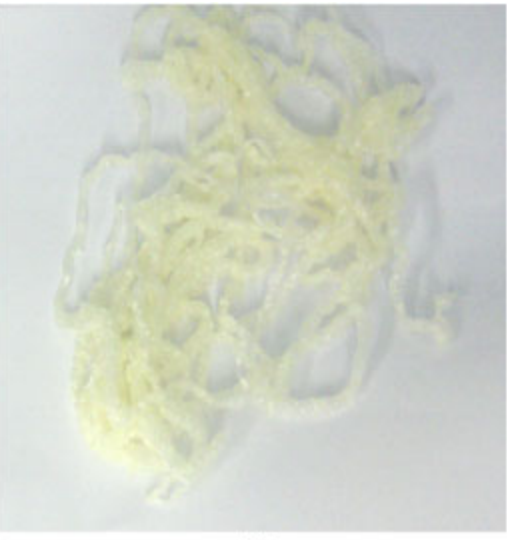

(B)

Figure 5. E100 CAR extrudates; (A) 6CAR20 and (B) 9CAR20SC.
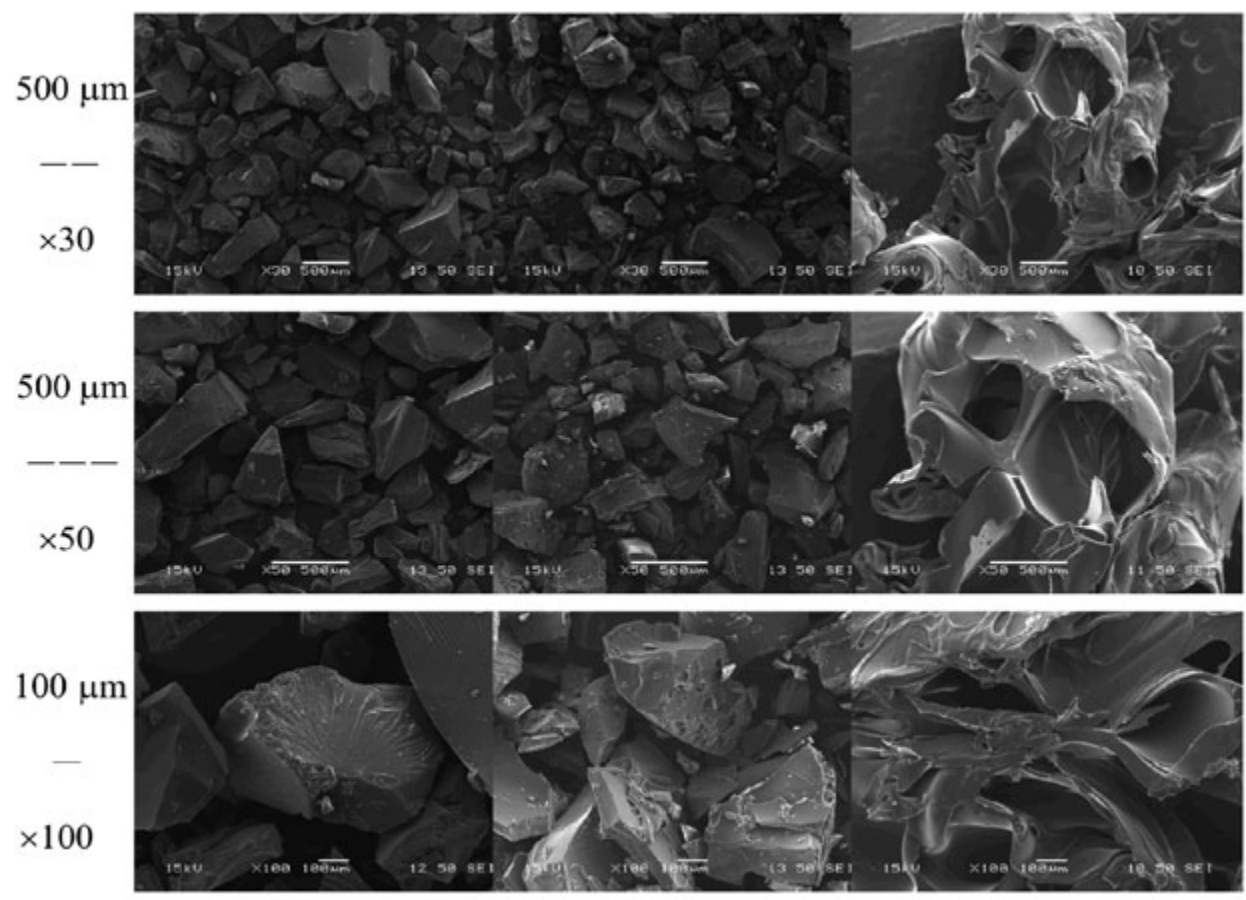

(A)

(C)

Figure 6. Scanning electron microscopy images of the extrudates; (A) milled 1CARO, (B) milled 5CAR5SC, and (C) 9CAR20SC. 
availability to the dissolving medium, which may increase the dissolution rate. This effect may be particularly effective for the sample with $20 \%$ of CAR, for which an important opened porosity is present in coarser particles.

\section{Fourier transform infrared spectrometry}

The extruded products were analyzed by FTIR spectrometry in order to check their possible degradation under the processing conditions. The results are shown in Fig. 7. Compared with the untreated pristine components, their spectra are combined in the spectrum of the extrudate, in which no new peak could be detected. It suggests that no detectable decomposition occurred during the extrusion.

Carvedilol has two common polymorphic crystalline forms. These are CAR form I and form II. ${ }^{[18,19]}$ In the absorption region of $\mathrm{O}-\mathrm{H}$ and $\mathrm{N}-\mathrm{H}$ stretching vibration, CAR form II has one strong band at $\sim 3340 \mathrm{~cm}^{-1}$, and CAR form I has two strong bands at $\sim 3250 \mathrm{~cm}^{-1}$ and $3450 \mathrm{~cm}^{-1}$. E100 has only two small peaks in this region.

In the spectra of E100 CAR extrudates, beside the appearing peaks of CAR around $1600 \mathrm{~cm}^{-1}$, one broader peak was observable from 3300 to $3450 \mathrm{~cm}^{-1}$, which demonstrates the intermolecular interaction between E100 and CAR. It suggests that CAR is not in crystalline form because the characteristic peaks of crystalline phases of the drug (form I and form II) are not present in the spectra. The broad peak indicates probably that CAR is present in amorphous form. This deduction corresponds to the results of Pokharkar et al. ${ }^{[20]}$ Further analyses were made by polarized light microscopy and X-ray diffraction in order to confirm that CAR is really in amorphous form in the extrudates.

\section{Polarized light microscopy}

The birefringent CAR crystals are well observable using polarized light microscopy because of the different color of the background (Fig. 8), which is the result of the double refraction of the polarized light. In contrast, the amorphous materials (E100 and amorphous CAR) exhibit the same color as the background.

The investigations of crystalline CAR and the extrudates made by polarized light microscope confirmed that there was no detectable crystalline phase in the extrudates. Moreover, the extrudates did not display any apparent inhomogeneities. It suggested again that the extrudates are amorphous.

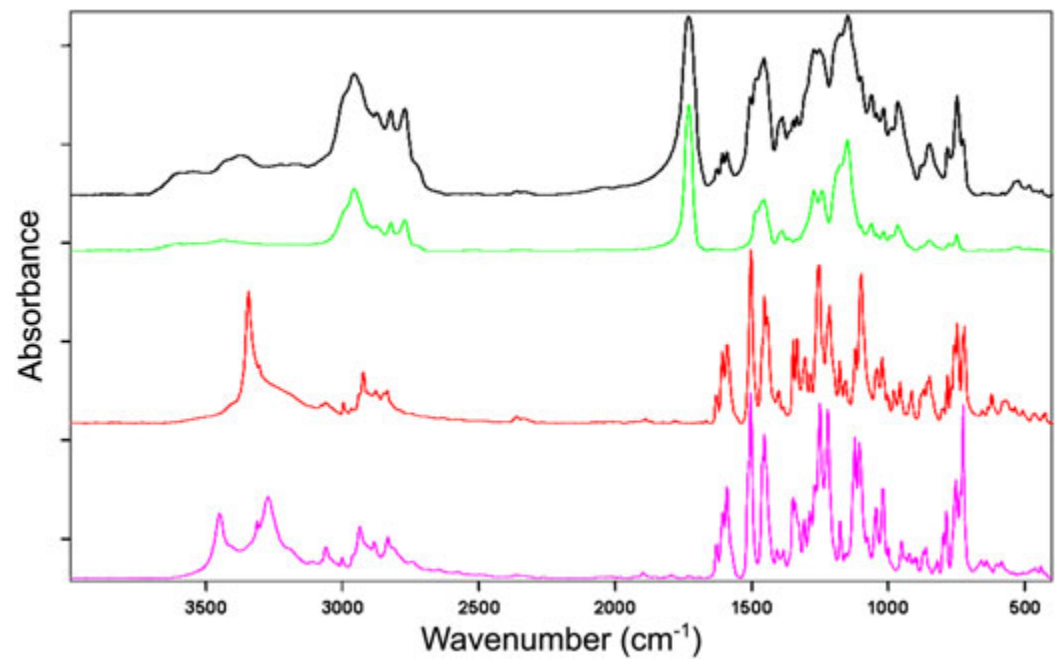

Figure 7. Fourier transform infrared spectra; (A) 9CAR20SC milled, (B) E100 powder, (C) CAR form II, and (D) CAR form I.
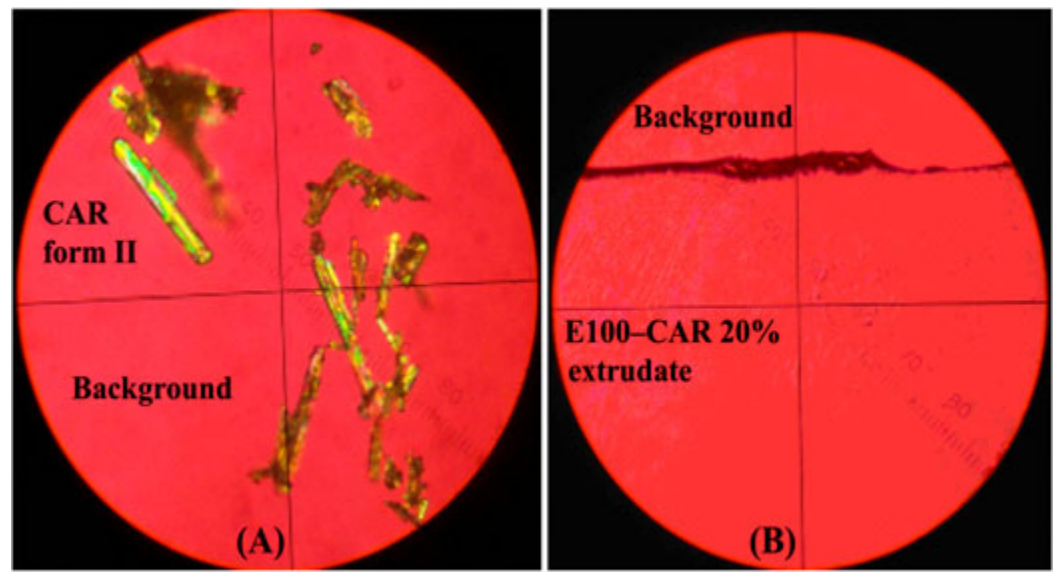

Figure 8. Polarized light microscopic images; (A) CAR form II and (B) 6CAR20. 


\section{X-ray diffraction}

Being a well-established method to characterize and distinguish crystalline and amorphous materials, X-ray diffraction was used to characterize the morphological changes of CAR induced by extrusion. After grinding, the plots of the extrudates prepared in experiments 6CAR20 and 9CAR20SC were compared with those of the individual components and their physical mixtures (Fig. 9). Although CAR preserved its form II polymorphic structure in the physical mixtures, it is transformed to fully amorphous form when extruded with amorphous E100 matrix. There was no sharp peak of crystalline CAR in the diffractograms of the extrudates in contrast to the physical mixture of the polymer matrix and the crystalline drug.

\section{Capillary electrophoresis}

The dissolved drug was investigated by capillary electrophoresis. Information is provided by number, integral, and appearance time of peaks of the UV spectra recorded by the diode-array detector.

The results showed that there is just one peak in the electrophoregram of the extrudates, as well as in the reference (pure CAR), which confirms the chemical stability of CAR during the extrusion process (Fig. 10). The migration time changed, which is probably due to presence of E100. Indeed, E100 is a cationic polymer, which can modify the surface charges of the silica capillary and the electro-osmotic flow.

The UV spectra of each studied sample at the peak of the analyzed substance were the same, proving that there is no (detectable) degraded CAR in the sample (Fig. 11).

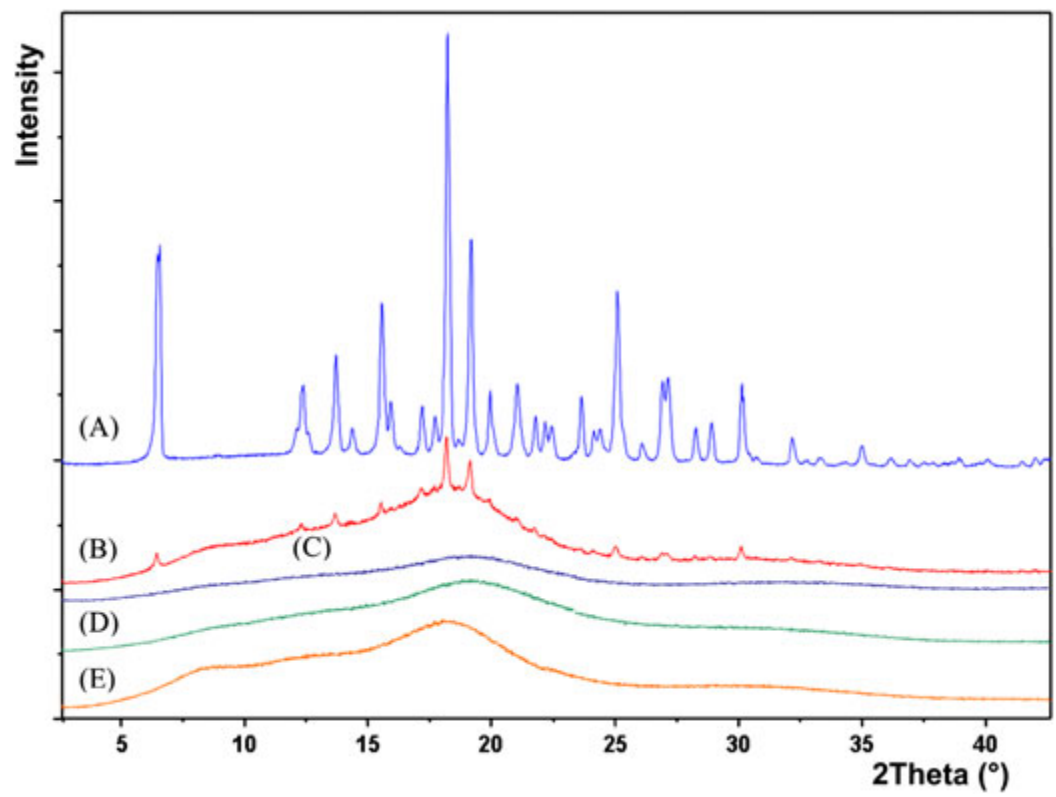

Figure 9. X-ray diffractograms; (A) CAR form II, (B) physical mixture of E100 CAR 5\%, (C) 9CAR20SC milled, (D) 6CAR20 milled, and (E) E100 powder.

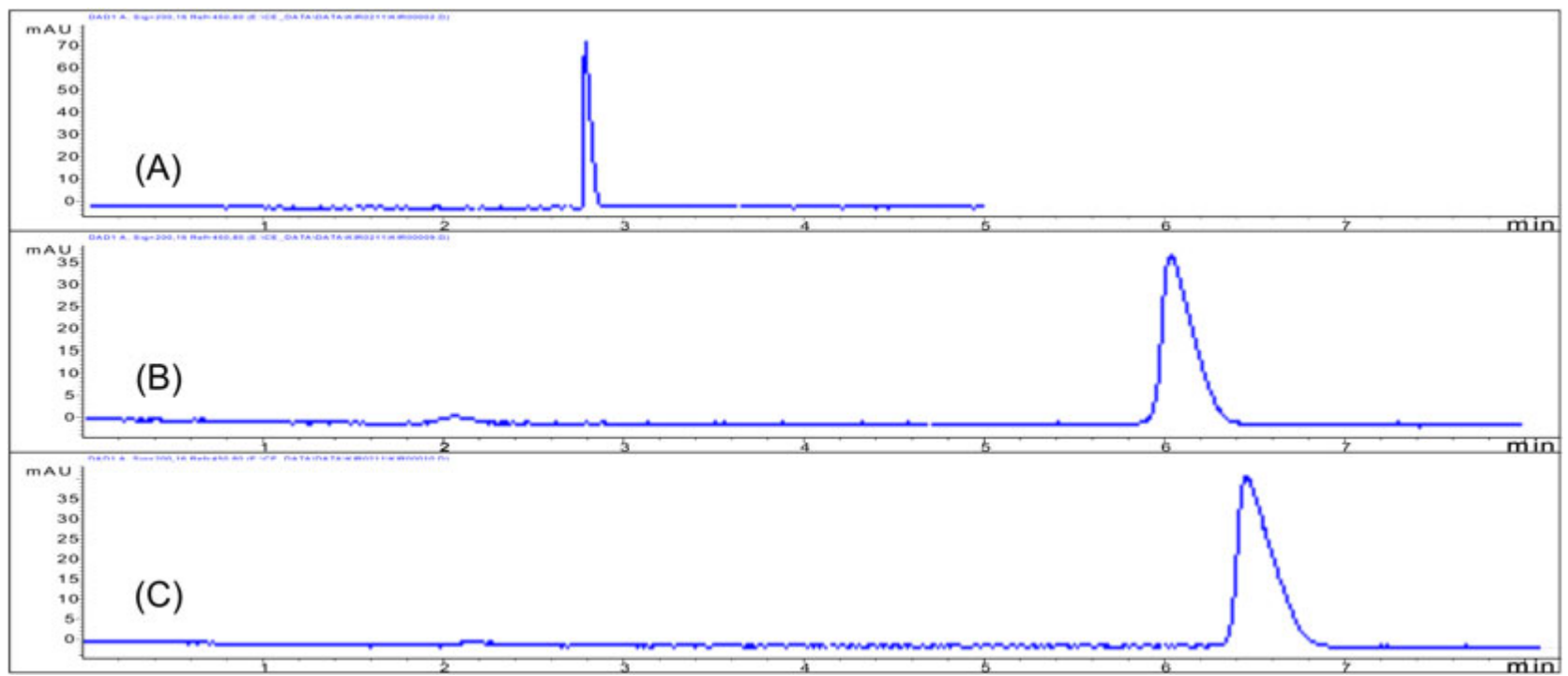

Figure 10. Electropherograms; (A) pure CAR, (B) 9CAR20SC, and (C) 6CAR20. 


\section{Raman microspectrometry}

Raman mapping was performed to characterize the homogeneity of CAR in the E100 matrix. The reference sample was again the physical mixture of the E100 powder and CAR. The inhomogeneous distribution of CAR in the physical mixture is very well observable and is not surprising as each component preserved its size during the mixing process (Fig. 12B). The homogeneous distribution observable in the Raman maps of the extrudates seems to be, however, more uniform than expected based on other extrusion products. ${ }^{[21]}$ Figure 12(A) illustrates that the distribution of CAR is almost perfectly homogeneous because of the extrusion process. Both components can be seen at the same time on the measured area. The figure on the left corresponds to the CAR, with spectral concentrations between $28 \%$ and $33 \%$ in all measured points (this is why it is green in every pixel, see color scaling). The figure on the right shows the distribution of the E100 on the same area, which is again almost perfectly homogeneous. The color scaling is the same in each figure so the pictures of the physical mixture and the extrudate can be directly compared with each other.

The relative standard deviation (RSD) of the calculated ratio of the substances was found to be less than $3 \%$ in cases of the conventional extrudate and $\mathrm{scCO}_{2}$-aided extrudate, whereas the RSD for the physical mixture was more than $45 \%$ (Table 2). The slight difference between the RSDs of two types of extrudates is comparable to the error of the Raman-mapping method. Compared with recent relevant published results, the RSD value of the samples prepared by melt extrusion is significantly lower than in the case of high-shear granulation (6\%) and fluid-bed granulation (17\%). ${ }^{[22]}$ It means that extrusion technology is very effective in homogenization compared with the widely used traditional processes of granulation. Achieving appropriate homogeneity is a serious challenge especially in the case of the solid dosage forms with low dosage rate $(<2 \%)$, such as hormonecontaining drugs. Application of extrusion technology for formulation of these types of drugs might be useful because of very effective homogenization.

\section{Drug content}

The drug content of the extrudates, determined with UV spectrophotometer, corresponded in all cases to the initially introduced CAR, and the RSD (1.31\%) of the measured contents was under the established limit of U.S. Pharmacopeia (6\%). ${ }^{[23]}$

\section{In vitro dissolution and drug content determination}

The in vitro dissolution of the different samples exhibited significant differences. The dissolution curves are shown in Fig. 13. Unprocessed crystalline CAR (curve C) shows moderate dissolution rate, which could be dramatically improved by HME with E100. 100\% was dissolved within 5 min (curves A and B). It was found that the E100 matrix governs the dissolution rate of the extrudates. CAR molecules dissolved simultaneously with the E100 matrix because the drug, being in amorphous form, does not need any additional action to overcome the crystal lattice energy. It is consistent with the fact that CAR is molecularly dispersed or nearly molecularly dispersed in the E100 matrix.

In the very first minutes, the dissolution of the milled foamed sample is even slightly more rapid in comparison with the unfoamed samples. This is probably because there is an inner porosity, which results in an increased surface area accessible to the solvent: the dissolution rate depending on the surface area of the material exposed to the dissolution medium. ${ }^{[24]}$

It appears that the use of HME is a very efficient way to improve the dissolution rate of a drug dispersed in a polymer matrix. In addition, the use of $\mathrm{scCO}_{2}$ gives a tool to enhance this dissolution rate.

\section{CONCLUSION}

In this work, fast-dissolving formulation of a poorly water-soluble drug against hypertension, CAR, was achieved by conventional and $\mathrm{ScCO}_{2}$-assisted $\mathrm{HME}$ process using Eudragit E100 as a polymer matrix. The manufactured fine solid dispersions of CAR

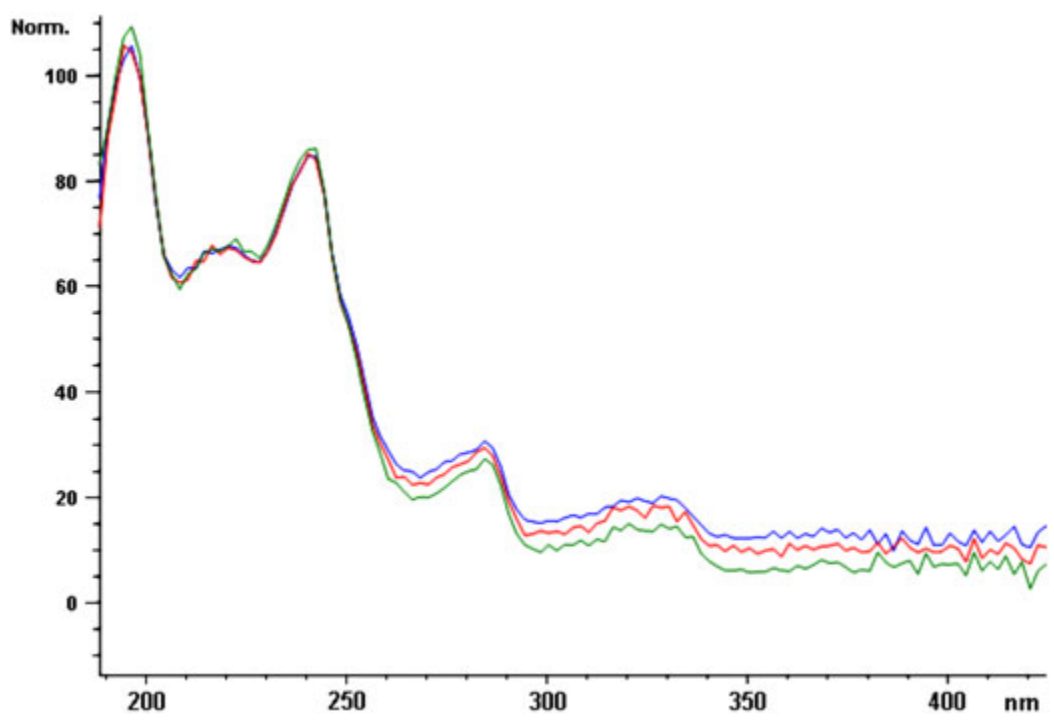

Figure 11. The UV spectra recorded at the peaks detected during capillary electrophoresis analyses; (A) CAR Form II, (B) 9CAR20SC, and (C) 6CAR20. 

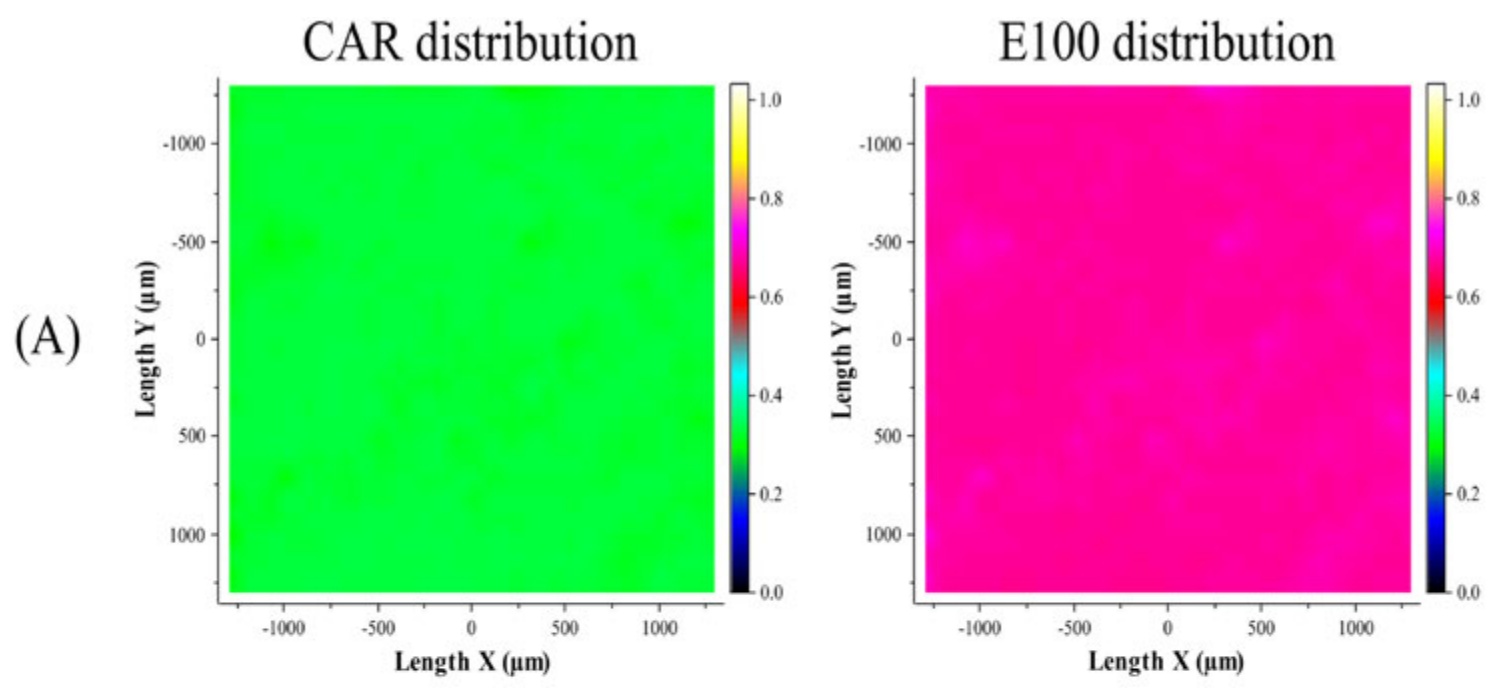

(B)
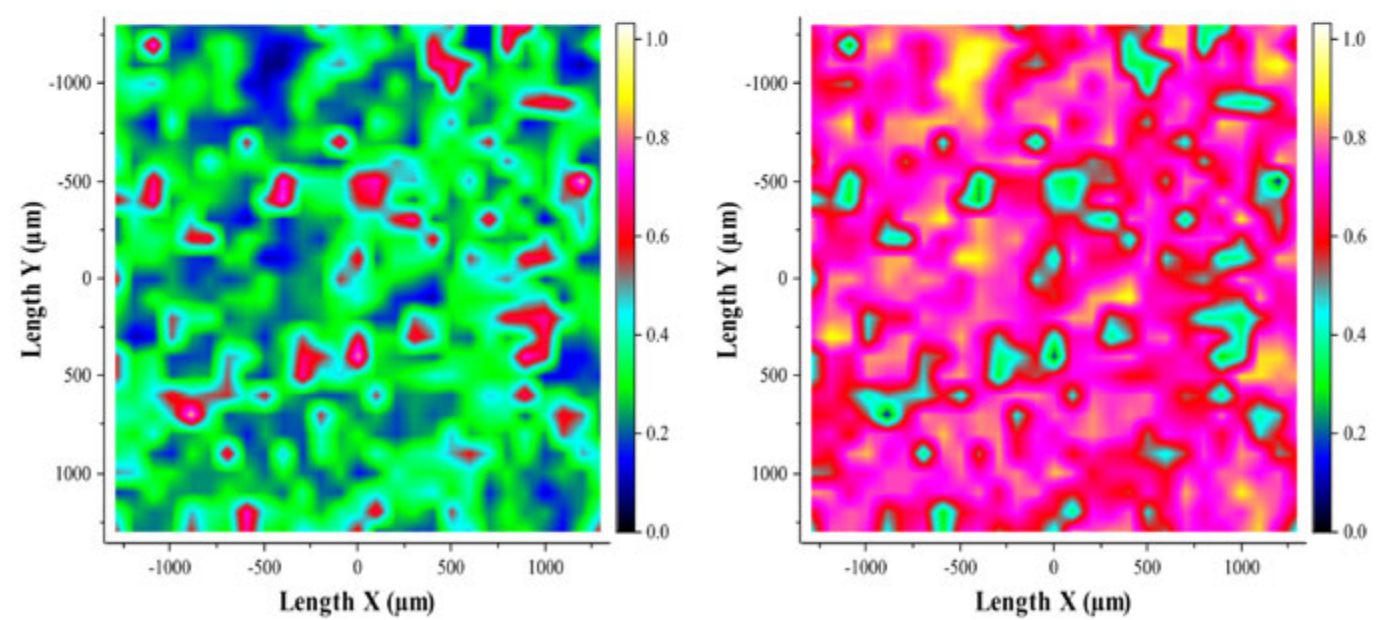

Figure 12. Raman maps; (A) physical mixture E100 CAR 20\% and (B) 6CAR20.

Table 2. Results of statistical evaluation of Raman mappings

\begin{tabular}{|lccc|} 
Statistical attribute & Extrudate (6CAR20) & Supercritical extrudate (9CAR20SC) & Physical mixture (CAR 20\%) \\
\hline Mean & 0.324 & 0.330 & 0.319 \\
Standard deviation & 0.00605 & 0.00979 & 0.14426 \\
Relative standard deviation (\%) & 1.87 & 2.95 & 45.25 \\
Minimum observed score & 0.28410 & 0.29439 & 0.06996 \\
Maximum observed score & 0.33283 & 0.35228 & 0.86459 \\
Range (maximum minimum) & 0.04873 & 0.05790 & 0.79463 \\
CAR, carvedilol. & & & \\
\hline
\end{tabular}

in Eudragit E stabilize the drug in its amorphous form. This was demonstrated by means of several analytical methods, polarized light microscopy, Raman microspectrometry, FTIR spectrometry, and X-ray diffractometry. The dissolution-improving efficiency was also due to the matrix of Eudragit $\mathrm{E}$ : its dissolution rate governing the rate of the drug release. Moreover, mild operating conditions and high productivity of the extrusion technology could be achieved by decreasing the viscosity with the aid of
$\mathrm{scCO}_{2}$ as a temporary plasticizer. Upon processing, no degradation of the drug could be observed.

A potential future perspective of $\mathrm{scCO}_{2}$-aided melt extrusion is the introduction of lipophilic drug into the extruder together with $\mathrm{scCO}_{2}$ as a solution. This process can be promising for preparation of solid formulations with low dosage such as hormones where achieving appropriate homogeneity and dissolution is a serious challenge for pharmaceutical technologists. 


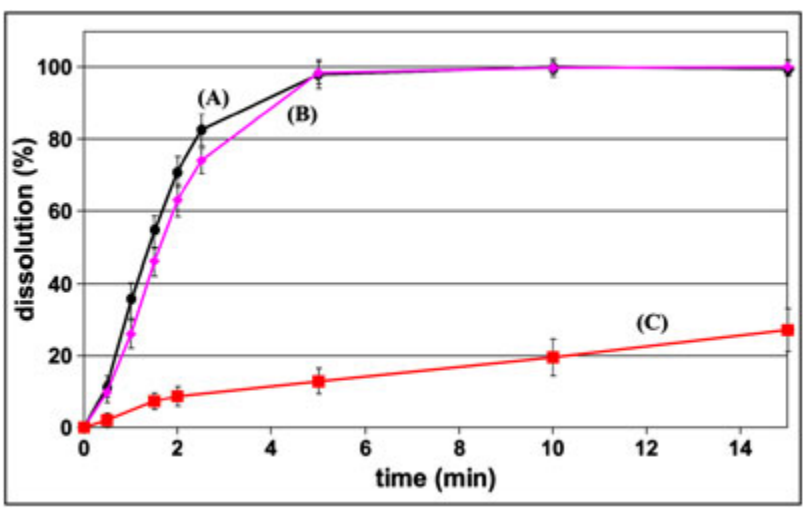

Figure 13. Dissolution profiles, (A) 9CAR20SC milled, (B) 6CAR20 milled, (C) crystalline CAR.

\section{Acknowledgements}

This research was support by OTKA Research Fund (code K76346) and ERA Chemistry (code NN 82426). The authors would like to express their special thanks to Zsuzsa Szabó for her generous support of Zsombor Kristóf Nagy's scholarship. This work is connected to the scientific program of the "Development of quality-oriented and harmonized $\mathrm{R}+\mathrm{D}+\mathrm{I}$ strategy and functional model at BME" project. This project is supported by the New Hungary Development Plan (Project ID: TÁMOP-4.2.1/B-09/1/ KMR-2010-0002).

\section{REFERENCES}

[1] C. Rauwendaal, Polymer Extrusion. Hanser Publishers, Munich, Germany, 2001.

[2] J. Breitenbach, Eur. J. Pharm. Biopharm. 2002, 54, 107117.
[3] J. W. McGinity, M. A. Repka, J. J. Koleng, F. Zhang, Hot-melt Extrusion Technology, Encyclopedia of Pharmaceutical Technology (3rd Ed). Informa healthcare, New York, London, 2007, 20042020.

[4] M. Sauceau, D. Ponomarev, C. Nikitine, E. Rodier, J. Fages, Supercritical Fluid and Materials. INPL, Vandoeuvre, France, 2007, 217237.

[5] M. Dittgen, M. Durrani, K. Lehmann, STP Pharma. Sci. 1997, 7, 403437.

[6] R. C. Rowe, P. J. Sheskey, P. J. Weller, Handbook of Pharmaceutical Excipients. Pharmaceutical Press, London, UK, 2006.

[7] K. Six, G. Verreck, J. Peeters, M. Brewster, G. V. Mooter, J. Pharm. Sci. 2004, 93, 124131.

[8] G. Verreck, A. Decorte, H. Li, D. Tomasko, A. Arien, J. Peeters, P. Rombaut, G. Van den Mooter, M. E. Brewster, J. Supercrit. Fluids 2006, 38, 383391.

[9] C. Nikitine, E. Rodier, M. Sauceau, J. J. Letourneau, J. Fages, J. Appl. Polym. Sci. 2010, 115, 981990.

[10] C. Nikitine, E. Rodier, M. Sauceau, J. Fages, Chem. Eng. Res. Des. 2009, 87, 809816

[11] D. Ponomarev, M. Sauceau, C. Nikitine, E. Rodier, J. Fages, Proceedings of the 11th European Meeting on Supercritical Fluids, Barcelona (Spain), 2008. http://www.isasf.net/meetings/proceedings.html

[12] M. Sauceau, J. Fages, A. Common, C. Nikitine, E. Rodier, Prog. Polym. Sci. 2011, in press. doi:10.1016/j.progpolymsci.2010.12.004

[13] P. C. Stafylas, P. A. Sarafidis, Vasc. Health Risk Manage. 2008, 4, 23.

[14] T. Loftsson, S. B. Vogensen, C. Desbos, P. Jansook, AAPS PharmSciTech 2008, 9, 425430.

[15] S. Kalimuthu, A. Yadav, Int. J. Pharm. Tech. Res. 2009, 1, 179183.

[16] U. Ubaidulla, M. V. S. Reddy, K. Ruckmani, F. J. Ahmad, R. K. Khar, AAPS PharmSciTech 2007, 8, 1320.

[17] C. Nikitine, M. Sauceau, F. Léonardi, E. Rodier, J. Fages. Mesures rheologiques sur un biopolymere, 42 ème Colloque du Groupe Français de Rhéologie, Clermont-Ferrand, France, 2007.

[18] P. Beyer, E. Reinholz, EP 0893440 A1, 1999.

[19] J. Aronhime, S. Ben-Valid, B. Dolitzky, S. Finogueev, J. Hildesheim, WO 02/00216 A1, 2002.

[20] V. B. Pokharkar, L. P. Mandpe, M. N. Padamwar, A. A. Ambike, K. R. Mahadik, A. Paradkar, Powder Technol. 2006, 167, 2025.

[21] G. Verreck, A. Decorte, K. Heymans, J. Adriaensen, D. Cleeren, A. Jacobs, D. Liu, D. Tomasko, A. Arien, J. Peeters, Eur. J. Pharm. Sci. 2005, 26, 349358.

[22] B. Vajna, I. Farkas, A. Szabó, Z. Zsigmond, G. Marosi, J. Pharm. Biomed. Anal. 2010, 51, 3038.

[23] U.S. Pharmacopeia, USP-NF General Chapter <905> Uniformity of Dosage Units 2007.

[24] A. A. Noyes, W. R. Whitney, J. Am. Chem. Soc. 1897, 19, 930934. 